\title{
Sugar and fat intake among children in Scotland: what is needed to reach the dietary targets?
}

\author{
Geraldine McNeill $1,2, *$, Lindsey F Masson ${ }^{1}$, Leone CA Craig ${ }^{1,2}$, Jennie I Macdiarmid ${ }^{2}$, \\ Bridget A Holmes ${ }^{3}$, Michael Nelson ${ }^{3}$ and Christine Sheehy ${ }^{4}$ \\ 'Population Health Section, Institute of Applied Health Sciences, University of Aberdeen, Foresterhill, Aberdeen \\ AB25 2ZD, UK: ${ }^{2}$ Rowett Institute of Nutrition and Health, University of Aberdeen, Aberdeen, UK: ${ }^{3}$ Nutritional \\ Sciences Division, King's College London, London, UK: ${ }^{4}$ Scottish Centre for Social Research, Edinburgh, UK
}

Submitted 19 January 2009: Accepted 20 October 2009: First published online 8 December 2009

\begin{abstract}
Objective: To assess the intake and sources of non-milk extrinsic sugars (NMES) and fat among children in Scotland in relation to socio-economic status, and to estimate the changes in diet required to achieve recommended levels of intake. Design: Cross-sectional survey with diet assessed by semi-quantitative FFQ.

Setting: Eighty postcode sectors across Scotland.

Subjects: Children ( $n$ 1398) aged 3-17 years recruited from the Child Benefit register ( $76 \%$ of those contacted).

Results: The mean intake of NMES of $17 \cdot 4$ (95\% CI $17 \cdot 0,17 \cdot 8) \%$ food energy was considerably higher than the UK recommended population average of $11 \%$ food energy. The mean intake of total fat of $32 \cdot 9$ (95\% CI $32 \cdot 7,33 \cdot 2) \%$ food energy met the recommended population average of no more than $35 \%$ food energy, while the mean intake of SFA of $13 \cdot 8$ (95\% CI $13 \cdot 7,14 \cdot 0) \%$ food energy was above the recommended population average of no more than $11 \%$ food energy. Despite clear socio-economic gradients in the mean daily consumption of many 'healthy' and 'unhealthy' food groups, socio-economic differences in NMES as a percentage of food energy were limited and there was no significant variation in the intake of total fat or SFA as a percentage of food energy with socio-economic status. Modelling of the data showed that removing sugar-sweetened soft drinks and increasing fruit and vegetable intake by $50 \%$ would not restore the intake of NMES and SFA to recommended levels.

Conclusions: Major changes in the intake of many food groups will be required to bring the NMES and saturated fat intake in line with current dietary recommendations.
\end{abstract}

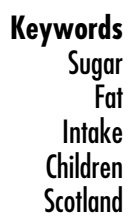

In the UK, extrapolation of current trends suggests that by 2050 a quarter of all children under 20 years of age will be classified as obese ${ }^{(1)}$. The urgent need for early prevention of excess weight gain in childhood has drawn attention to the diet of children, and in particular to their intake of foods rich in fat, SFA and sugars. Non-milk extrinsic sugars (NMES) ${ }^{(2)}$ include table sugars and added sugars (e.g. in soft drinks, cakes and confectionery) as well as sugars in fruit juice, which are less satiating and increase insulin levels more than the same amount of sugar in whole fruit $^{(3)}$. High NMES intake has been associated with higher intake of fat ${ }^{(4,5)}$ and poor dental health in children ${ }^{(6)}$. Sugar-sweetened soft drinks have received particular attention in relation to dental health as they are frequently consumed between meals and their acidic nature contributes to dental erosion ${ }^{(7)}$. Although the evidence for the suggestion that 'liquid calories' can overcome satiety signals is limited ${ }^{(8)}$, studies in adolescents have reported that consumption of sugar-sweetened soft drinks is associated with subsequent weight gain ${ }^{(9)}$ and that a reduction in intake has a beneficial effect on body weight $^{(10)}$. A systematic review of the literature in 2006 concluded that there was strong evidence for an independent role of sugar-sweetened beverages in the promotion of weight gain and obesity in children and adolescents $^{(11)}$, although two more recent reviews highlighted the lack of evidence from intervention studies which would support this conclusion ${ }^{(12,13)}$.

In Scotland surveys in the 1980s found that 15-yearolds consumed soft drinks, confectionery and crisps more frequently than 35 -year-olds ${ }^{(14)}$ and were more likely to consume sweet drinks and less likely to consume milk and vegetables than children in England and Wales ${ }^{(15)}$. The WHO Health and Behaviour of School-aged Children (HBSC) study reported that in 2001/2 children in Scotland ranked second highest out of twenty-five countries for 
daily consumption of sweet drinks and third highest for daily consumption of sweets ${ }^{(16)}$. Data from the 1998 sweep of the HBSC also showed that the proportion of children consuming high-fat and high-sugar foods daily was higher among those in less affluent families ${ }^{(17)}$. This is in line with a study of 11-year-olds in the West of Scotland in 1994/5 which found that less healthy eating patterns were associated with socio-economic deprivation ${ }^{(18)}$. The 2003 Scottish Health Survey also reported higher consumption of sweets and chocolates, crisps and savoury snacks, chips and non-diet soft drinks and lower consumption of fruit and vegetables in children living in more deprived areas ${ }^{(19)}$, but a study of 7-8-year-olds in Edinburgh carried out in 1991/2 found that total sugar as a percentage of energy was significantly lower in children in the manual social classes compared with those in the non-manual social classes ${ }^{(20)}$. Lack of availability of affordable, healthy foods in deprived areas has been highlighted in the past but the existence of 'food deserts' in deprived areas has recently been questioned $^{(21)}$. A survey of food retailing across Scotland in 2005-7 found that availability of healthy foods was more strongly influenced by the size of food stores than neighbourhood deprivation and that in urban areas the price of healthy foods did not differ between affluent and deprived neighbourhoods ${ }^{(22)}$.

In 2006 the Food Standards Agency Scotland commissioned a survey of diet of children across Scotland with the primary aim of comparing the intake of NMES and fat with recommended levels. In line with the commitment of the Scottish Government to reducing health inequalities, a secondary aim of the survey was to explore variation in NMES and fat intake according to socio-economic status.

\section{Methods}

The full report of the survey, which contains details of the survey methodology and copies of the field-work documents, has been published online ${ }^{(23)}$.

\section{Sample selection}

Using the Department of Work and Pensions (DWP) Child Benefit Register, a named sample of 2800 children aged between 3 and 16 years on 1 May 2006 was drawn from eighty postcode sectors across Scotland. One child per household was selected. Three hundred and two children were excluded by the DWP as sensitive or being involved in other surveys. Two hundred and fifty-three of the remaining 2498 children were classified as 'out of scope' due to incorrect or ineligible addresses ( $n$ 204), failure to contact after four house calls ( $n$ 38) or a variety of other less common reasons.

\section{Data collection}

The initial invitation letters mailed to parents/guardians provided a FREEPHONE telephone number and a FREEPOST address for parents or guardians who wished to opt out, and $146 \mathrm{did}$ so. All other parents or guardians were mailed a second letter with an FFQ. Field workers contacted the family and arranged a visit at home at which the completed FFQ was checked in the presence of the parent or guardian and the child. If the FFQ had not been completed a further copy was left with the family with a reply-paid envelope. Height and weight were measured in the home by the field workers and data on demographic characteristics, physical activity and dental health were collected by computerassisted personal interview. Field work was carried out between May and September 2006.

\section{FFQ}

The FFQ used for children aged 3-11 years was designed for completion by the parent or guardian. The food list of 140 foods or drinks was modified from the list used in the Scottish Collaborative Group FFQ for adults (http:// www.foodfrequency.org.uk). The modifications focused on foods and drinks commonly consumed by children which were identified from responses on FFQ completed in previous research projects involving children. An earlier version of the children's questionnaire showed good agreement for total sugar, total fat and SFA (all as \% food energy) between the FFQ and diet diary in eighty pre-school children ${ }^{(24)}$. For young people aged 12-17 years the questionnaire was designed to be completed by the young person with help from a parent or guardian and included six additional items to capture intake of coffee and alcoholic drinks. For each food or drink on both questionnaires a measure (e.g. 'one slice' or 'one tablespoon') was defined and a single colour photograph showing examples of measures was included in the instructions. Respondents were asked to estimate the usual frequency of consumption of each food using one of nine frequency options which ranged from 'rarely or never' to '7 or more measures per day'. Questionnaires with more than ten missing responses were excluded from the analysis. Data were entered manually and a $10 \%$ check of the data entry found an error rate of $0.4 \%$.

All items on the FFQ were divided into thirty-three food or drink groups as used in the Low Income Diet and Nutrition Survey ${ }^{(25)}$, apart from a few instances in which the grouping of foods on the FFQ led to minor differences in the definitions of these groups. Energy and nutrient intakes were estimated from an in-house calculation package based on the National Diet and Nutrition Survey nutrient database as used in the Low Income Diet and Nutrition Survey ${ }^{(25)}$.

To assess the validity of the questionnaire used in this population, a randomly selected subgroup of 311 children was invited to complete a $4 \mathrm{~d}$ non-weighed diet diary, and 153 completed diaries were received for which there was a corresponding FFQ.

\section{Socio-economic status}

Socio-economic status was assessed using the 2006 Scottish Index of Multiple Deprivation (SIMD), a measure 
of neighbourhood socio-economic status based on twentyseven indicators from seven domains (income, housing, employment, health, crime, education, access to services) ${ }^{(26)}$. The data zones are based on individual postcodes containing a median of 750 people. SIMD scores from the 6505 data zones are categorised into quintiles, ranging from 1 (least deprived) to 5 (most deprived).

\section{Overweight and obesity}

Measured weight and height were used to calculate BMI, which was compared with the UK 1990 percentile charts $^{(27)}$. Overweight was defined as BMI equal to or above the 85th percentile but below the 95th percentile; and obesity was classified as BMI equal to or above the 95th percentile.

\section{Data analysis}

For analysis children were classified into three groups (3-7 years, 8-11 years, 12-17 years) using their age at the date of the home visit. To exclude extreme values for energy intake, FFQ with energy intake below the $2 \cdot 5$ th percentile or above the $97 \cdot 5$ th percentile of energy intake for the age group were excluded from the analysis.

Statistical analyses were carried out using the SPSS version $12 \cdot 5$ (SPSS Inc., Chicago, IL, USA) and Stata/SE 9.216 (StataCorp., College Station, TX, USA) statistical software packages. Variables which were not normally distributed were transformed to a normal distribution using the LNSKEW command in Stata to allow computation of means and $95 \%$ confidence intervals before backtransformation to the original scale, with the exception of data on the food sources of nutrients which were not transformed to ensure that the total contribution of the food groups to nutrient intake was $100 \%$ in all cases. All data were weighted to take account of selection and nonresponse bias. Differences between the sexes in nutrient intake were assessed by the $t$ test. Linear associations between food or nutrient intake and age group, SIMD quintile and BMI category (neither overweight nor obese, overweight excluding obese, obese) were assessed by linear regression. Logistic regression was used to assess the association between overweight (including obese) and SIMD quintile.

\section{Etbics and research governance}

At time of the field work neither the University of Aberdeen nor the Scottish Centre for Social Research required formal ethical review of surveys in healthy populations, but all data collection and management was carried out in accordance with the research governance and quality assurance policy of the Institute of Applied Health Sciences at the University of Aberdeen (http:// www.abdn.ac.uk/iahs/research-governance/governance. shtml) and the Social Research Association guidelines (http://www.the-sra.org.uk/documents/pdfs/ethics03.pdf).

\section{Results}

\section{Survey response}

Recruitment and response to the survey is outlined in Fig. 1. One thousand seven hundred children were interviewed at home, of whom 1491 returned an FFQ of which 1267 were reviewed by the field worker to minimise missing data; the remaining 225 questionnaires were returned by mail either before or after the visit. FFQ were also received by mail for twenty-one children for whom the field worker was unable to schedule a home visit after repeated attempts. The response rate for the home visit was $76 \%$ of those contacted or $61 \%$ of the initial sample drawn by DWP. The response rate for completion of the FFQ was $67 \%$ of those contacted or $54 \%$ of the initial sample drawn by DWP. The response rate was very similar between boys and girls and between age subgroups for all components of the survey, but for the FFQ completion was lower among those in the most deprived SIMD quintile (58\%) compared with those in the other four quintiles (69 to $71 \%)^{(23)}$. All FFQ were checked for completeness on receipt at the office: fifty-one questionnaires were excluded as they had more than ten missing responses and seventy were excluded as having extreme energy intake values; thus data on the diet of 1391 children were used for analysis.

\section{Comparison of dietary assessment methods}

In the 153 children for whom both an FFQ and a diet diary were available, energy intake was on average $10.5 \%$ higher by the FFQ than the diet diary $(P<0 \cdot 001)$ but for NMES, total fat and SFA expressed as a percentage of food energy the difference was under $5 \%$ and the values were not significantly different between the two methods. Further details of the comparison of the methods are given in the full survey report ${ }^{(23)}$.

\section{Main sources of energy, sugar and fat}

Overall mean energy intake was $7 \cdot 68 \mathrm{MJ} / \mathrm{d}(1825 \mathrm{kcal} / \mathrm{d})$ of which $17 \cdot 4(95 \%$ CI $17 \cdot 0,17 \cdot 8) \%$ was derived from NMES; $32 \cdot 9$ (95\% CI 32.7, 33.2) \% from total fat and $13 \cdot 8$ $(95 \%$ CI $13 \cdot 7,14 \cdot 0) \%$ from SFA. There were no significant differences in the percentage of food energy from these nutrients between boys and girls, but the percentage of food energy from NMES was higher in older children than in younger children $(19 \cdot 1 \%$ in $12-17$-yearolds $v .16 \cdot 9 \%$ in $8-11$-years-olds and $15 \cdot 8 \%$ in $3-7$-yearolds; $P$ for linear trend $<0 \cdot 001$ ). The percentage energy from total fat did not differ significantly between the age groups whereas the percentage of food energy from SFA was slightly lower in older children than in younger children $(13.6 \%$ in $12-17$-year-olds $v$. $13.7 \%$ in $8-11$ year-olds and $14 \cdot 2 \%$ in $3-7$-year-olds; $P$ for linear trend $<0 \cdot 001)$.

Of the thirty-three food and drink groups the major contributors to energy intake were biscuits, cakes and 


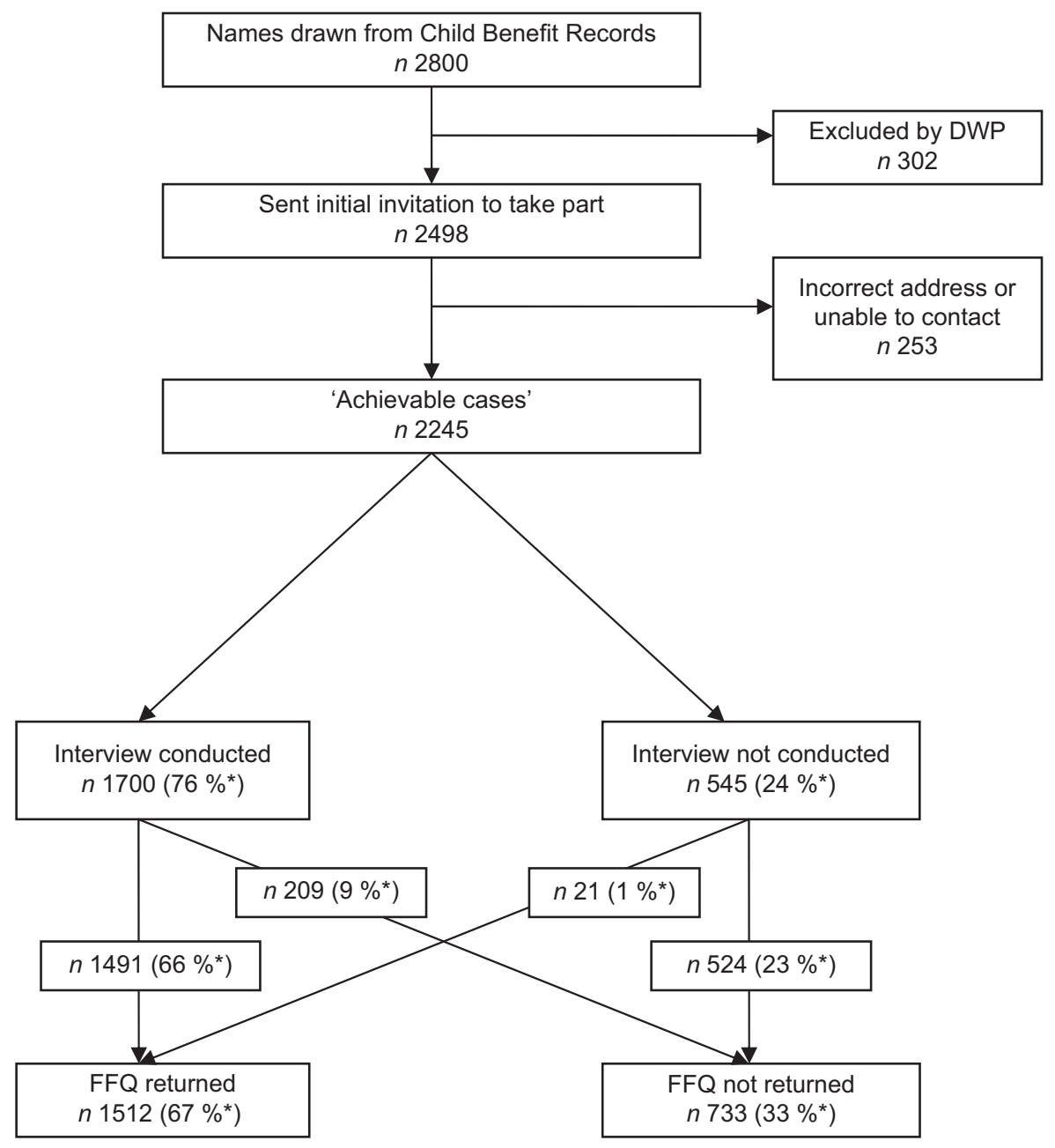

Fig. 1 Recruitment and response to the survey (DWP, Department of Work and Pensions; *values are \% of achievable cases)

pastries (10\%), bread (excluding wholemeal; 9\%), milk and cream (8\%) and crisps and savoury snacks (7\%). The major contributors to NMES intake were sugar-sweetened soft drinks (23\%), confectionery (15\%), biscuits, cakes and pastries (13\%), yoghurt and fromage frais (10\%) and fruit juice $(10 \%)$. For total fat the main sources were biscuits, cakes and pastries (11\%), crisps and savoury snacks (11\%), milk and cream (10\%) and processed meats (9\%), while for SFA the main sources were milk and cream (14\%), biscuits, cakes and pastries (12\%), crisps and savoury snacks (10\%), processed meats (8\%) and cheese $(8 \%)$.

\section{Intake of foods in relation to socio-economic status}

Table 1 shows the mean daily intake of selected food groups among consumers (defined as children who consumed one or more items in this food group at least once a month) in the SIMD quintiles. There were clear differences in intake between the quintiles for many of the food groups: the daily intake of sugar-sweetened soft drinks in the most deprived group was almost twice that of the least deprived group, while the intake of fruit juice was half that of the least deprived group. However, for biscuits, cakes and pastries, milk and cream, yoghurt and fromage frais and cheese there was no significant difference in the mean daily intake across the quintiles.

\section{Intake of nutrients in relation to socio-economic status}

Table 2 shows the intake of energy and NMES, total fat and SFA as a percentage of food energy in the SIMD quintiles. Energy intake in the most deprived quintile was $6 \%$ higher than that in the least deprived quintile, and for NMES as a percentage of energy the value in the most deprived quintile was $13 \%$ higher than the intake in the least deprived quintile. The intake of total fat and SFA as a percentage of food energy showed no relationship with socio-economic status.

\section{Overweight and obesity}

Overall $14 \%$ of children were classed as overweight (excluding obese) and $17 \%$ as obese. The proportion of children who were overweight or obese ranged from 
Table 1 Average daily intake ( $\mathrm{g} / \mathrm{d}$; mean and $95 \%$ confidence interval) of selected food and drink groups among consumers according to socio-economic deprivation: Scottish children $\left(n 1373^{\star}\right)$ aged $3-17$ years, May-September 2006

\begin{tabular}{|c|c|c|c|c|c|c|c|c|c|c|c|c|c|}
\hline \multirow[b]{3}{*}{ Food or drink group } & \multirow{3}{*}{$\begin{array}{c}\% \text { consumers } \\
\text { (children eating at } \\
\text { least once a month) }\end{array}$} & \multicolumn{10}{|c|}{ Scottish Index of Multiple Deprivation (SIMD) quintile } & \multirow{3}{*}{$\begin{array}{l}\text { Intake in 5th quintile } \\
\text { as percentage of } \\
\text { intake in 1st quintile }\end{array}$} & \multirow{3}{*}{$\begin{array}{l}P \text { for } \\
\text { linear } \\
\text { trend }\end{array}$} \\
\hline & & \multicolumn{2}{|c|}{$\begin{array}{l}\text { 1st (least deprived) } \\
\quad n 315\end{array}$} & \multicolumn{2}{|c|}{$\begin{array}{l}\text { 2nd } \\
n 278\end{array}$} & \multicolumn{2}{|c|}{$\begin{array}{c}\text { 3rd } \\
n 259\end{array}$} & \multicolumn{2}{|c|}{$\begin{array}{c}\text { 4th } \\
n 268\end{array}$} & \multicolumn{2}{|c|}{$\begin{array}{l}\text { 5th (most deprived) } \\
n 253\end{array}$} & & \\
\hline & & Mean & $95 \% \mathrm{Cl}$ & Mean & $95 \% \mathrm{Cl}$ & Mean & $95 \% \mathrm{Cl}$ & Mean & $95 \% \mathrm{Cl}$ & Mean & $95 \% \mathrm{Cl}$ & & \\
\hline Sugar-sweetened soft drinks & 91 & 123 & 104,144 & 137 & 108,173 & 145 & 124,169 & 189 & 163,218 & 234 & 204,268 & 190 & $<0.001$ \\
\hline Chips and fried potatoes & 97 & 17 & 16,19 & 20 & 17,22 & 24 & 21,26 & 24 & 22,27 & 29 & 27,32 & 171 & $<0.001$ \\
\hline Crisps and savoury snacks & 97 & 16 & 14,19 & 19 & 16,21 & 20 & 18,23 & 24 & 21,27 & 26 & 23,30 & 163 & $<0.001$ \\
\hline Confectionery & 98 & 19 & 17,20 & 20 & 18,23 & 21 & 18,24 & 25 & 22,28 & 29 & 26,32 & 153 & $<0.001$ \\
\hline Processed meats & 97 & 22 & 20,23 & 24 & 22,26 & 26 & 24,28 & 30 & 26,33 & 31 & 28,33 & 141 & $<0.001$ \\
\hline Bread (excluding wholemeal) & 99 & 50 & 46,54 & 50 & 45,55 & 48 & 43,52 & 55 & 49,62 & 56 & 51,62 & 112 & 0.031 \\
\hline Biscuits, cakes and pastries & 99 & 36 & 33,39 & 37 & 33,41 & 34 & 31,37 & 35 & 32,39 & 36 & 32,40 & 100 & 0.837 \\
\hline Milk and cream & 97 & 245 & 222,270 & 241 & 217,267 & 252 & 232,275 & 235 & 210,262 & 246 & 220,274 & 100 & 0.909 \\
\hline Yoghurt and fromage frais & 96 & 78 & 68,88 & 71 & 62,81 & 93 & 82,104 & 80 & 70,90 & 65 & 56,75 & 83 & 0.306 \\
\hline Cheese & 89 & 11 & 9,12 & 10 & 8,11 & 10 & 9,11 & 11 & 10,13 & 9 & 8,11 & 82 & 0.572 \\
\hline Fruit (excluding fruit juice) & 98 & 146 & 130,163 & 130 & 118,143 & 136 & 125,148 & 138 & 124,153 & 112 & 99,127 & 77 & 0.007 \\
\hline Vegetables (excluding potatoes) & 96 & 65 & 57,73 & 55 & 48,63 & 55 & 49,62 & 45 & 39,52 & 43 & 39,48 & 66 & $<0.001$ \\
\hline Fruit juice (including smoothies) & 88 & 87 & 76,100 & 72 & 60,86 & 59 & 51,68 & 58 & 49,67 & 41 & 36,46 & 47 & $<0.001$ \\
\hline
\end{tabular}

${ }^{*}$ Eighteen children with complete FFQ did not have information on SIMD.

Table 2 Intake of energy and non-milk extrinsic sugars (NMES), total fat and SFA as a percentage of total energy in relation to socio-economic deprivation: Scottish children ( $n$ 1373 $)$ aged 3-17 years, May-September 2006

\begin{tabular}{|c|c|c|c|c|c|c|c|c|c|c|c|c|c|}
\hline \multirow[b]{3}{*}{ Food or drink group } & \multirow{3}{*}{$\begin{array}{l}\text { Recommended } \\
\text { intake }(\% \text { food } \\
\text { energy) })^{(25)}\end{array}$} & \multicolumn{10}{|c|}{ Scottish Index of Multiple Deprivation (SIMD) quintile } & \multirow{3}{*}{$\begin{array}{l}\text { Intake in 5th quintile } \\
\text { as percentage of } \\
\text { intake in 1st quintile }\end{array}$} & \multirow{3}{*}{$\begin{array}{l}P \text { for } \\
\text { linear } \\
\text { trend }\end{array}$} \\
\hline & & \multicolumn{2}{|c|}{$\begin{array}{l}\text { 1st (least deprived) } \\
n 315\end{array}$} & \multicolumn{2}{|r|}{$\begin{array}{l}\text { 2nd } \\
n 278\end{array}$} & \multicolumn{2}{|c|}{$\begin{array}{l}\text { 3rd } \\
n 259\end{array}$} & \multicolumn{2}{|c|}{$\begin{array}{c}\text { 4th } \\
n 268\end{array}$} & \multicolumn{2}{|c|}{$\begin{array}{c}\text { 5th (most deprived) } \\
n 253\end{array}$} & & \\
\hline & & Mean & $95 \% \mathrm{Cl}$ & Mean & $95 \% \mathrm{Cl}$ & Mean & $95 \% \mathrm{Cl}$ & Mean & $95 \% \mathrm{Cl}$ & Mean & $95 \% \mathrm{Cl}$ & & \\
\hline Energy $(\mathrm{MJ} / \mathrm{d})$ & $\mathrm{n} / \mathrm{a}$ & $7 \cdot 51$ & $7 \cdot 26,7 \cdot 76$ & $7 \cdot 49$ & $7 \cdot 24,7 \cdot 76$ & $7 \cdot 44$ & $7 \cdot 20,7 \cdot 69$ & 8.05 & $7 \cdot 63,8 \cdot 49$ & $7 \cdot 98$ & $7 \cdot 66,8 \cdot 33$ & 106 & 0.002 \\
\hline NMES (\% food energy) & 11 & $16 \cdot 3$ & $15 \cdot 7,17 \cdot 0$ & $17 \cdot 4$ & $16 \cdot 5,18 \cdot 3$ & $16 \cdot 8$ & $16 \cdot 1,17 \cdot 5$ & $18 \cdot 1$ & $17 \cdot 3,18 \cdot 9$ & $18 \cdot 4$ & $17 \cdot 6,19 \cdot 2$ & 113 & 0.001 \\
\hline Total fat (\% food energy) & 35 & $32 \cdot 8$ & $32 \cdot 3,33 \cdot 3$ & $32 \cdot 7$ & $32 \cdot 3,33 \cdot 2$ & $32 \cdot 9$ & $32 \cdot 3,33 \cdot 5$ & $32 \cdot 8$ & $32 \cdot 2,33 \cdot 3$ & $33 \cdot 4$ & $32 \cdot 8,34 \cdot 1$ & 102 & $0 \cdot 164$ \\
\hline SFA (\% food energy) & 11 & $13 \cdot 8$ & $13 \cdot 4,14 \cdot 2$ & $13 \cdot 8$ & $13 \cdot 6,14 \cdot 1$ & $13 \cdot 8$ & $13 \cdot 5,14 \cdot 1$ & $13 \cdot 8$ & $13 \cdot 5,14 \cdot 1$ & $14 \cdot 0$ & $13 \cdot 6,14 \cdot 3$ & 101 & 0.545 \\
\hline
\end{tabular}

n/a, not applicable.

*Eighteen children with complete FFQ did not have information on SIMD. 
Table 3 Estimated impact of changes in intake of selected food and drink groups on the mean intake of energy, non-milk extrinsic sugars (NMES), total fat and SFA: Scottish children ( $n$ 1391) aged 3-17 years, May-September 2006

\begin{tabular}{|c|c|c|c|c|}
\hline Dietary change & Energy $\mathrm{MJ} / \mathrm{d}$ & $\begin{array}{c}\text { NMES g/d } \\
(\% \text { food energy })^{\star}\end{array}$ & $\begin{array}{c}\text { Total fat } \mathrm{g} / \mathrm{d} \\
\text { (\% food energy) }+\end{array}$ & $\begin{array}{c}\text { SFA g/d } \\
\text { (\% food energy) } \dagger\end{array}$ \\
\hline $\begin{array}{l}\text { Initial level } \\
\text { a) Remove sugar-sweetened soft drinks } \\
\text { b) Increase fruit by } 50 \% \\
\text { c) Increase vegetables } \$ \text { by } 50 \%\end{array}$ & $\begin{array}{r}7 \cdot 68 \\
-0.38 \\
+0.23 \\
+0.12\end{array}$ & $\begin{array}{c}83 \cdot 0(17 \cdot 3) \ddagger \\
-19 \cdot 1 \\
+1 \cdot 2 \\
-\end{array}$ & $\begin{aligned} 67 \cdot 7 & (32 \cdot 6) \ddagger \\
& - \\
& - \\
+ & 1 \cdot 4\end{aligned}$ & $\begin{aligned} 28 \cdot 6 & (13 \cdot 8) \\
& - \\
& - \\
+ & 0 \cdot 3\end{aligned}$ \\
\hline ALL OF THE ABOVE (a-c) & $7 \cdot 65$ & $65 \cdot 1(13 \cdot 6)$ & $69 \cdot 1(33 \cdot 4)$ & $28.9(14 \cdot 0)$ \\
\hline $\begin{array}{l}\text { d) Decrease confectionery by } 50 \% \\
\text { e) Decrease crisps and savoury snacks by } 50 \% \\
\text { f) Decrease biscuits, cakes and pastries by } 50 \% \\
\text { g) Decrease processed meats by } 50 \% \\
\text { h) Decrease yoghurt and fromage frais by } 50 \% \\
\text { i) Increase bread (all types) by } 50 \% \\
\text { j) Increase pasta, rice and pizza by } 50 \% \\
\text { k) Increase other potatoesll by } 5 \%\end{array}$ & $\begin{array}{l}-0.19 \\
-0.27 \\
-0.38 \\
-0.19 \\
-0.19 \\
+0.42 \\
+0 \cdot 19 \\
+0.08\end{array}$ & $\begin{array}{l}-6 \cdot 2 \\
- \\
-5 \cdot 4 \\
- \\
-4 \cdot 1 \\
- \\
- \\
-\end{array}$ & $\begin{array}{l}-2 \cdot 0 \\
-3 \cdot 7 \\
-3 \cdot 7 \\
-3 \cdot 0 \\
-1 \cdot 7 \\
+1 \cdot 4 \\
+1 \cdot 7 \\
-\end{array}$ & $\begin{array}{l}-1 \cdot 0 \\
-1 \cdot 4 \\
-1 \cdot 7 \\
-1 \cdot 1 \\
-1 \cdot 0 \\
+0 \cdot 4 \\
+0 \cdot 4 \\
-\end{array}$ \\
\hline ALL OF THE ABOVE (a-k) & $7 \cdot 12$ & $49 \cdot 4(11 \cdot 1)$ & $58 \cdot 1(30 \cdot 2)$ & $23.5(12 \cdot 2)$ \\
\hline
\end{tabular}

*\% Food energy calculated as $[(\mathrm{g}$ NMES $\times 16 \mathrm{~kJ} / \mathrm{g}) /($ energy intake in $\mathrm{kJ})] \times 100$.

$\uparrow \%$ Food energy calculated as $[(\mathrm{g}$ total fat or SFA $\times 37 \mathrm{~kJ} / \mathrm{g}) /($ energy intake in $\mathrm{kJ})] \times 100$.

$\ddagger$ Values differ slightly from those in the text which are the average of the individual values for intake of NMES and total fat as a percentage of food energy. $\S$ Includes salad vegetables in mayonnaise or dressing, e.g. coleslaw.

IIBoiled, mashed or baked potatoes.

$25 \%$ in the least deprived SIMD quintile to $32 \%$ in the most deprived quintile. There was a significant linear association between the prevalence of overweight and obesity and socio-economic status ( $P$ for linear trend $=$ $0 \cdot 021)$ although the highest prevalence $(36 \%)$ was in the third quintile of SIMD. No association between overweight and obesity and the intake of food or drink groups which were major sources of NMES, total fat or SFA was found, apart from a lower intake of biscuits, cakes and pastries in obese children $(P$ for linear trend $=0 \cdot 010)$. There was no significant association between overweight and obesity and intake of energy or NMES as a percentage of food energy, but there was a slightly lower intake of total fat and SFA as a percentage of food energy in the overweight and obese children compared with the children who were neither overweight nor obese ( $P$ for linear trend $=0.032$ for total fat and 0.004 for SFA).

\section{Changes in intake of food groups needed to achieve recommendations for non-milk extrinsic sugars, fat and SFA}

Using the data on consumption of the food and drink groups, the impact of changes in intake on the intake of NMES, total fat and SFA as a percentage of food energy were estimated. The results are shown in Table 3, which demonstrates that complete removal of sugar-sweetened soft drinks and a 50\% increase in whole fruit and vegetable intake would make a major contribution to reducing NMES intake towards the recommended level, but even these substantial changes would not be sufficient to meet the population target for NMES. To achieve the population targets for NMES and SFA, a reduction in other foods high in NMES and SFA coupled with an increase in foods rich in complex carbohydrate will be required.

\section{Discussion}

The mean intake of NMES of $17 \cdot 4 \%$ food energy in both boys and girls was considerably higher than the UK recommended population average of $11 \%$ food energy $^{(28)}$, but was close to values of $16 \cdot 4-17 \cdot 1 \%$ reported in the UK-wide National Diet and Nutrition Survey of young people aged 4-18 years in $1997^{(29)}$ and in children aged 2-18 years who took part in the Low Income Diet and Nutrition Survey (involving UK households in the lowest $15 \%$ of material deprivation) in $2003-5^{(25)}$. In the National Diet and Nutrition Survey the percentage energy from NMES generally decreased with age: it was highest in 7-10-year-old boys $(17 \cdot 5 \%)$ and 4-6-year-old girls (17.6\%) and lowest in 15-18-year-old boys (15.8\%) and girls $(15 \cdot 3 \%)$, unlike the present survey in which the percentage was lowest in the 3-7-year-old boys (16.0\%) and girls (15.6\%) and rose with age to $19 \cdot 0 \%$ in $12-17$ year-old boys and $19 \cdot 1 \%$ in $12-17$-year-old girls. Due to differences in the age groups, year of survey and survey methods it is difficult to attribute this change in age trends to intakes of specific foods or drinks, but the high values in the older children in the present survey suggest that NMES intake in adolescents is increasing and needs to be monitored particularly carefully in future.

The intake of total fat of $32.9 \%$ food energy in boys and $33.0 \%$ in girls in the present survey was satisfactory as it was below the recommended UK population average of $35 \%{ }^{(28)}$ and also lower than the values reported in children in the other UK-wide surveys which were in the range of $35-36 \%^{(25,29)}$. Although different dietary assessment methods were used in these surveys, we found no significant difference in total fat as a percentage of food energy between the FFQ and a $4 \mathrm{~d}$ non-weighed diet diary in a sub-sample of the participants in the present 
survey ${ }^{(23)}$. We therefore believe it more likely that the lower intake of total fat as a percentage of food energy in the present survey compared with the earlier surveys suggests a real decrease over time, as observed in children in North-East England between 1980 and 2000 (30) and in household-level data for Scotland between 1996 and $2003 / 4^{(31)}$. SFA intake of $13.9 \%$ food energy in boys and $13.7 \%$ in girls was above the UK recommended level of $11 \%{ }^{(28)}$ but close to values of $14 \cdot 0-14 \cdot 3 \%$ reported in the UK-wide surveys ${ }^{(25,29)}$.

The clear socio-economic differences in the consumption of many foods which are rich in NMES, total fat or SFA is consistent with the patterns seen in the 1998 HBSC survey ${ }^{(16)}$ and the children in the 2003 Scottish Health Survey ${ }^{(19)}$. The smaller difference in NMES intake and lack of difference in total fat and SFA intake between the socio-economic groups is similar to findings of the National Diet and Nutrition Survey of young people, which found few significant differences in nutrient intake between geographical regions of the UK despite significant differences in the intake of different food groups $^{(29)}$. Another piece of evidence supporting the limited socio-economic difference in the intake of NMES and lack of difference in total fat and SFA intake is the fact that the results of the present study were similar to those recorded in the Low Income Diet and Nutrition Survey ${ }^{(25)}$. Household-level data for Scotland from the Expenditure and Food Survey also show a limited gradient in NMES intake and no socio-economic gradient in total fat or SFA intake (all expressed as a percentage of food energy) ${ }^{(31)}$. The contrast between the gradients for foods $v$. nutrients is likely to reflect the fact that for a number of food groups which are major contributors to NMES, total fat and SFA intake, such as biscuits, cakes and pastries and milk and cream, the amounts consumed showed no relationship to socio-economic status, while for other foods such as fruit juice, yoghurt and fromage frais and cheese, which are considered healthy foods particularly for children but are often high in NMES or SFA, the intake was higher in children in the less deprived areas (see Table 1). This suggests that it may be important in health promotion campaigns to suggest that these foods should only be consumed in moderation. It also suggests that surveys which, for reasons of brevity, assess the intake of perceived 'healthy' or 'unhealthy' foods as opposed to all foods may overestimate the magnitude of differences in macronutrient intake between groups of different socio-economic status.

The prevalence of overweight (excluding obesity) and obesity in the children in the present survey was very similar to the values of $16.5 \%$ overweight (excluding obese) and $15.9 \%$ obese in children aged $2-15$ years in the 2003 Scottish Health Survey, which also found the highest prevalence of overweight (including obesity) in boys and girls combined in the middle SIMD quintile ${ }^{(19)}$. The lack of relationship between overweight and obesity and the intake of high-fat or high-sugar foods or the intake of NMES, total fat and SFA as a percentage of food energy is consistent with other cross-sectional studies in children $^{(32,33)}$. Although there is some evidence that under-reporting of energy intake in overweight or obese adults occurs with $\mathrm{FFQ}^{(34)}$, in children the evidence for this is confined to diet diaries ${ }^{(35,36)}$; however, we cannot rule out the possibility that this reporting bias affected the results of the present survey. Alternative explanations for the lack of difference in nutrient intake between the weight groups are that the overweight and obese children were reporting eating habits which had changed as a result of their weight gain, or that the weight gain in the overweight and obese children was accounted for by lower energy expenditure in physical activity. The proportion of overweight and obese children who met the physical activity recommendation of at least $60 \mathrm{~min} / \mathrm{d}$ for seven days per week ${ }^{(37)}$ was significantly lower than that in the neither overweight nor obese children $(P<0 \cdot 001)^{(23)}$, but again this could reflect a decrease in physical activity in response to overweight rather than a causal association.

The response to the survey of $76 \%$ of those contacted completing the interview and $67 \%$ completing both the FFQ and the interview was comparable to the $80 \%$ cooperation with a dietary interview and $64 \%$ completion of a $7 \mathrm{~d}$ dietary record in the UK-wide National Diet and Nutrition Survey of young people aged 4-18 years in $1997^{(29)}$. While the FFQ was sent by mail for completion prior to the field worker's visit, in 305 cases the questionnaire had not been completed at this stage so another copy was left in the home for completion and return by mail, but only 150 were eventually received. The field workers had not been instructed to request completion of the FFQ during the visit as this would have extended the interview from 60 to $90 \mathrm{~min}$, but this could be considered in future surveys to ensure a high response rate.

In the present survey an FFQ was chosen to assess diet rather than the more usual weighed or non-weighed diet diary because of the lower respondent burden and lower likelihood of response bias by socio-economic status: in the FFQ-diet diary comparison sub-study $31 \%$ of those in the most deprived SIMD quintile returned the diary compared with $56 \%$ in the least deprived quintile, a greater difference than the rate of $58 \%$ in the most deprived quintile $v .71 \%$ in the least deprived quintile for the FFQ response. As FFQ require less trained staff time for analysis the costs for a large survey are also considerably lower than using a diet diary, but this can only be justified if the FFQ provides robust estimates of the variables of interest. Although the comparison of the two methods in a subset of 153 participants highlighted the fact that energy intake was overestimated by the FFQ relative to the non-weighed diary, this difference may have been partly accounted for by underestimation of energy intake by the diet diary, which has been reported 
in other studies in children ${ }^{(35,36)}$. The comparison of methods showed that the main variables of interest in this survey, i.e. percentage energy from NMES, total fat and SFA, were not significantly different between the two methods. The comparison study did not have sufficient statistical power to assess whether there were differences in the agreement between methods between subgroups in the study population, so the possibility that differences in reporting bias influenced the comparisons of intake between subgroups needs to be borne in mind.

The fact that NMES and SFA intakes were higher than recommended levels in all age, sex and socio-economic groups in the present survey highlights the need for dietary change in the whole population of children in Scotland. Table 3 illustrates that the magnitude of the change needed to reach recommended levels is substantial: cutting out all sugar-sweetened soft drinks and replacing the energy by increasing the intake of fruit and vegetables leads to some reduction in the NMES intake but no change in the SFA intake. Additional changes to reduce the intake of other foods which contribute to NMES and SFA and to replace the energy with increases in foods high in complex carbohydrates will also be needed. Although some of these other food groups do contribute to the intake of other nutrients which are important in the diets of children, in all cases there are less processed alternatives which are lower in NMES and SFA. In the 1997 children's National Diet and Nutrition Survey ${ }^{(29)}$ yoghurts and fromage frais accounted for $4 \%$ of total Ca intake in boys and $5 \%$ in girls, but dairy products combined (including yoghurt and fromage frais) contributed $6 \%$ of NMES intake in boys and $7 \%$ in girls, compared with $1 \%$ from fruits and nuts in both sexes; similarly, in both boys and girls, burgers, kebabs, sausages, meat pies and pastries accounted for $3 \%$ of total Fe intake but meat products (including coated chicken) accounted for $12 \%$ of total SFA intake, compared with only $7 \%$ from other meat and meat dishes. Such changes would require a shift away from pre-packaged snack and convenience foods, which are often heavily marketed to children, and towards fruit, vegetables and staple foods which may be less convenient or attractive although not necessarily more costly than the foods high in NMES and SFA. Achieving these substantial changes in children's eating habits across the population will require commitment from families, schools, retailers, advertisers and the local and national food policy makers who share the goal of improving the diet of children for longer-term population health.

\section{Acknowledgements}

The survey was funded by the Food Standards Agency Scotland, who contributed to the design of the study and approved the final manuscript but played no part in the data collection or analysis. The authors declare that they have no conflict of interest. G.McN., L.F.M. and C.S. conceived the study with input from other authors; C.S. supervised the data collection; L.C.A.C., J.I.M. and B.A.H. were responsible for the dietary analysis; L.F.M. carried out the statistical analysis and G.McN. drafted the manuscript which was reviewed by all authors. We thank Janet Kyle and Gladys McPherson of the University of Aberdeen for assistance with the analysis of the FFQ and Sarah Tipping at the National Centre for Social Research for assistance with the nutrient database and statistical analysis.

\section{References}

1. Butland B, Jebb S, Kopelman P et al. (2007) Tackling Obesities: Future Choices - Project Report. London: Department for Innovation, Universities and Skills.

2. Department of Health (1989) Dietary Sugars and Human Disease. London: HMSO.

3. Haber GB, Heaton KW, Murphy D et al. (1977) Depletion and disruption of dietary fibre. Effects on satiety, plasmaglucose and serum-insulin. Lancet ii, 679-682.

4. Emmett PM \& Heaton KW (1995) Is extrinsic sugar a vehicle for dietary fat? Lancet 345, 1537-1540.

5. Gibson SA (1997) Non-milk extrinsic sugars in the diets of pre-school children: association with intakes of micronutrients, energy, fat and NSP. Br J Nutr 78, 367-378.

6. Rennie KL \& Livingstone MB (2007) Associations between dietary added sugar intake and micronutrient intake: a systematic review. Br J Nutr 97, 832-841.

7. Moynihan P \& Petersen PE (2004) Diet, nutrition and the prevention of dental diseases. Public Health Nutr 7, 201-226.

8. Almiron-Roig E, Chen Y \& Drewnowski A (2003) Liquid calories and the failure of satiety: how good is the evidence? Obes Rev 4, 201-212.

9. Ludwig D, Peterson KE \& Gortmaker SL (2001) Relation between consumption of sugar-sweetened drinks and childhood obesity: a prospective, observational analysis. Lancet 257, 505-508.

10. Ebbeling CB, Feldman HA, Osganian SK et al. (2006) Effects of decreasing sugar-sweetened beverage consumption on body weight in adolescents: a randomized, controlled pilot study. Pediatrics 117, 673-680.

11. Malik VS, Schulze MB \& Hu FB (2006) Intake of sugarsweetened beverages and weight gain: a systematic review. Am J Clin Nutr 84, 274-288.

12. Gibson S (2008) Sugar-sweetened soft drinks and obesity: a systematic review of the evidence from observational studies and interventions. Nutr Res Rev 21, 134-137.

13. Wolff E \& Dansinger ML (2008) Soft drinks and weight gain: how strong is the evidence? Medscape J Med 10, 189.

14. Anderson AS, Macintyre S \& West P (1994) Dietary patterns among adolescents in the West of Scotland. Br J Nutr $\mathbf{7 1}$, $111-122$.

15. Crawley H (1997) Dietary and lifestyle differences between Scottish teenagers and those living in England and Wales. Eur J Clin Nutr 51, 87-91.

16. Currie C, Roberts C, Morgan A et al. (2007) Young People's Health in Context. Health and Behaviour in School-aged Children (HSBC) Study: International Report from the 2001/2002 Survey. Geneva: WHO.

17. Inchley J, Todd J, Bryce C et al. (2001) Dietary trends among Scottish schoolchildren in the 1990s. J Hum Nutr Diet 14, 207-216.

18. Sweeting H \& West P (2005) Dietary habits and children's family lives. J Hum Nutr Diet 18, 93-97. 
19. Bromley C, Sproston K \& Shelton N (editors) (2005) The Scottish Health Survey 2003. Edinburgh: The Stationery Office.

20. Ruxton CHS \& Kirk TR (1996) Relationships between social class, nutrient intake and dietary patterns in Edinburgh schoolchildren. Int J Food Sci Nutr 47, 341-349.

21. Macintyre S (2007) Deprivation amplification revisited: or, is it always true that poorer places have poorer access to resources for healthy diets and physical activity? Int J Behav Nutr Phys Act $\mathbf{4}, 32$.

22. Dawson J, Marshall D, Taylor M et al. (2008) Accessing Healthy Food: A Sentinel Mapping Study of Healthy Food Retailing in Scotland: Executive Summary. Aberdeen: Food Standards Agency Scotland; available at http:// www.food.gov.uk/multimedia/pdfs/accessfoodscotexec. pdf

23. Sheehy C, McNeill G, Masson LF et al. (2008) Survey of Sugar Intake among Children in Scotland. Aberdeen: Food Standards Agency Scotland; available at http://www.food. gov.uk/scotland/scotnut/scotsug

24. Craig LCA \& McNeill G (2006) Relative validity of a food frequency questionnaire for preschool children compared with a 4 d diet diary. Proc Nutr Soc 65, 39A.

25. Nelson M, Erens B, Bates B et al. (editors) (2007) Low Income Diet and Nutrition Survey. London: The Stationery Office.

26. The Scottish Government (2006) Scottish Index of Multiple Deprivation 2006: Technical Report. Edinburgh: Office of the Chief Statistician, Scottish Executive; available at http:// www.scotland.gov.uk/Publications/2006/10/13142913/0

27. Cole TJ, Freeman JV \& Preece MA (1995) Body mass index reference curves for the UK, 1990. Arch Dis Child 73, $25-29$.
28. Department of Health (1991) Dietary Reference Values for Food Energy and Nutrients for the United Kingdom. London: HMSO.

29. Gregory J, Lowe S, Bates CJ et al. (2000) National Diet and Nutrition Survey: Young People Aged 4 to 18 Years. London: The Stationery Office.

30. Rugg-Gunn AJ, Fletcher ES, Matthews JN et al. (2007) Changes in consumption of sugars by English adolescents over 20 years. Public Health Nutr 10, 354-363.

31. Wrieden WL, Barton KL, Armstrong J et al. (2006) A Review of Food Consumption and Nutrient Intakes from National Surveys in Scotland: Comparison to the Scottish Dietary Targets. Aberdeen: Food Standards Agency Scotland.

32. Rodriguez G \& Moreno LA (2006) Is dietary intake able to explain differences in body fatness in children and adolescents? Nutr Metab Cardiovas Dis 16, 294-301.

33. Gibson SA \& Neate D (2007) Sugar intake, soft drink consumption and body weight among British children: further analysis of National Diet and Nutrition Survey data with adjustment for underreporting and physical activity. Int J Food Sci Nutr 58, 445-460.

34. Lissner L, Troiano RP, Midthune D et al. (2007) OPEN about obesity: recovery biomarkers, reporting errors and BMI. Int J Obes (Lond) 31, 956-961.

35. Fisher JO, Johnson RK, Lindquist C et al. (2000) Influence of body composition on the accuracy of reported energy intake in children. Obes Rev 8, 597-603.

36. Rennie KL, Jebb SA, Wright A et al. (2005) Secular trends in under-reporting in young people. Br J Nutr 93, 241-247.

37. National Physical Activity Task Force (2003) Let's Make Scotland More Active: A Strategy for Physical Activity. Edinburgh: Scottish Executive; available at http:// www.scotland.gov.uk/library5/culture/lmsa-00.asp 